\title{
Frontotemporal Dementia: Change of Familial Caregiver Burden and Partner Relation in a Dutch Cohort of 63 Patients
}

\author{
Samantha Riedijk ${ }^{\mathrm{a}, \mathrm{b}}$ Hugo Duivenvoorden ${ }^{\mathrm{a}}$ Sonia Rosso $^{c}$ John Van Swieten ${ }^{c}$ \\ Martinus Niermeijer ${ }^{d}$ Aad Tibben $^{e}$ \\ Departments of a Medical Psychology and Psychotherapy, ${ }^{b}$ Clinical Genetics and ${ }^{\mathrm{C}}$ Neurology, Erasmus Medical \\ Centre, Rotterdam, ${ }^{d}$ Section of Clinical Genetics, Department of Anthropogenetics, University Medical Centre \\ Nijmegen-St. Radboud, Nijmegen, and ${ }^{e}$ Departments of Clinical Genetics and Neurology, Leiden University \\ Medical Centre, Leiden, The Netherlands
}

\section{Key Words}

Frontotemporal dementia - Caregiver burden, follow-up • Relationship quality

\begin{abstract}
Background/Aims: The current study examined the change of caregiver burden and the development of the quality of the partner relation in frontotemporal dementia (FTD). Methods: During a 2-year period, deterioration, behavioural problems, caregiver burden, general psychopathology, quality of life, social support, coping strategies and relationship quality were inspected in 63 FTD caregiver-care recipient dyads. Results: After 2 years patients reached maximum dementia severity with stable Neuropsychiatric Inventory levels. Contrary to expectations, caregiver burden decreased and psychological well-being remained stable. Coping style and social support changed unfavourably. Relationship closeness and getting along were preserved, whereas communication and sharing viewpoint on life were dramatically reduced. Conclusions: FTD caregivers need support in coping with the increasingly hopeless situation of their patients. Future research methods into caregiver burden should address response shift as a means for psychological adjustment.

Copyright $\odot 2008$ S. Karger AG, Basel
\end{abstract}

\section{Introduction}

Frontotemporal dementia (FTD) is the second most common type of presenile neurodegenerative dementia after Alzheimer's disease, and its prevalence is estimated to be 2.7/100,000 inhabitants in the Netherlands [1]. The early clinical features of FTD consist of frontal-systemrelated behavioural problems such as disinhibition and executive dysfunction, impairment in the regulation of personal conduct, loss of insight and emotional blunting. FTD patients progressively develop memory decline, loss of initiative and aphasia [2].

The care for patients with dementia before their institutionalization is known to represent a significant burden to the well-being and quality of life of family caregivers. According to Sorensen et al. [3] burden encompasses the strain of caregiving on psychological, physical, spiritual, social and financial well-being. Across the literature on caregiver burden, varying factors have been found to be associated with caregiver burden, and patient behavioural problems are consistently reported [4-8]. Behavioural problems related to the frontal system seem to be particularly burdening $[9,10]$. The few studies focusing on the course of neuropsychiatric disturbance in FTD found an increase in these behavioural problems during

\section{KARGER}

Fax +4161306 1234 E-Mail karger@karger.ch www.karger.com
S. Riedijk, MA

Department of Medical Psychology and Psychotherapy

Erasmus Medical Centre, PO Box 1738

NL-3000 DR Rotterdam (The Netherlands)

Tel./Fax +31 10408 9420, E-Mail s.riedijk@erasmusmc.nl 
Table 1. Overview of time intervals of data collection presented for each measure

\section{Baseline Months}

$\begin{array}{llll}6 & 12 & 18 & 24\end{array}$

\begin{tabular}{lccccc}
\hline Patients & & & & & \\
Domicile & $\times$ & $\times$ & $\times$ & $\times$ & $\times$ \\
GDS & $\times$ & & & & $\times$ \\
NPI & $\times$ & & & & $\times$ \\
\hline
\end{tabular}

Caregivers

NPI

Burden

Problems with physical health

Problems with mental health

Physical health on VAS

Mental health on VAS

SCL-90

SF-36

UCL

SSL

Quality relationship

$\begin{array}{ccccc}\times & & & & \times \\ \times & \times & \times & \times & \times \\ \times & & & & \times \\ \times & & & & \times \\ & \times & \times & \times & \\ & \times & \times & \times & \\ \times & & & & \times \\ \times & & & & \times \\ \times & & & & \times \\ \times & & & & \times \\ \times & & & & \times \\ & & & & \\ \end{array}$

GDS = Global Deterioration Scale; NPI = Neuropsychiatry Inventory; VAS = visual analogue scale; SCL-90 = 90-item Symptom Checklist; SF-36 = 36-item Short Form questionnaire; UCL = Utrecht Coping List; SSL = Social Support List.

the progression of FTD $[11,12]$, implying that as FTD severity progresses, caregiver burden in FTD might also increase as a function of behavioural disturbance. This study evaluates for the first time how caregiver burden in FTD unfolds over a period of 2 years.

In longitudinal and prospective studies on caregiver burden in other types of dementia (mostly Alzheimer's disease), it has been reported that caregivers generally show stable levels of depression and burden over time [13-16]. Also, despite increasing severity of dementia and other functional impairment of the patient, a reduction of depression is sometimes seen [14]. Quality of life was also found to be stable. However, longitudinal analysis of caregiver burden in FTD with its frontal symptoms might have a different impact on caregiver burden, but has not been studied to date. Our impression of caregiver burden from the clinic and from caregiver meetings is that this group of dementia caregivers feels particularly burdened, due to the frontal system manifestations of FTD and also due to the age of onset, which is when most caregivers are supposed to be actively partaking in society and still have to work to earn a living (as opposed to being retired). Therefore, the primary goal of the current study was to assess the change of caregiver burden in family caregivers of FTD patients over 2 years. In the current study, the definition of caregiver burden of Sorensen et al. [3] was employed, more specifically we assessed the psychological and social domains of caregiver burden.

The onset of dementia causes a significant role change within the relationship. The partner relationship gradually transforms from a mutual relationship into a caregiver-care recipient relationship, with consequently a lower quality of the relationship. A good relationship is known to buffer against caregiver burden [17-19]. Given the potentially more burdening features of FTD (i.e. behavioural problems, lack of insight, emotional blunting), caregivers will need to preserve some quality aspects of the relationship. Some studies have demonstrated that certain facets of the relationship, such as closeness, may be preserved or even improved in couples who are faced with dementia [20,21]. Therefore, the secondary goal of our study was to assess the evolution of the quality of the caregiver-care recipient relationship during the progression of FTD. By focusing on these aspects of caregiver burden and relationship quality we aimed to attain a detailed description of the needs of FTD caregivers during the progress of their task.

\section{Methods}

\section{Participants}

Neurological and psychiatric outpatient clinics and psychogeriatric nursing homes in the Netherlands were questioned annually about the presence of suspected FTD patients between January 1994 and June 2002. The clinical diagnosis was established according to the Lund-Manchester criteria [22] and supported by neuro-imaging and neuropsychological assessments [23]. At the time of the study, 111 patients fulfilled the criteria of FTD. Between December 2001 and June 2002, FTD patients and their primary family caregivers at home and in nursing homes were recruited for participation in our prospective study on caregiver burden.

The Medical Ethics Committee of the Erasmus Medical Centre approved of the study. Out of the 111 eligible cases, 24 of the primary caregivers could not be contacted because of death or departure from the country. Of the remaining 87 caregivers, 17 refused participation, 4 were ill and 3 did not respond to our letter. All in all, a total of 63 FTD patients and their primary family caregivers could be included in the study, representing a response rate of $72.4 \%$. All caregivers consented to participate, and their consent was also obtained for the investigation of their patients' characteristics.

Patient and caregiver assessments were carried out at baseline and after 24 months of follow-up, and consisted of administering a questionnaire and a structured interview. Between baseline and 24 months, 3 semi-structured interviews $(6,12$ and 18 months 
after baseline) were conducted by telephone to assess caregiver characteristics. Trained psychologists carried out the semi-structured interviews. Table 1 presents an overview of which data were assembled at which time points.

At baseline, the Neuropsychiatric Inventory (NPI) was filled out for all 63 patients. At 24 months, the NPI was filled out for 31 patients. Fourteen patients were deceased, 8 could not be contacted to administer the NPI at follow-up and 10 were lost to follow-up for unknown reasons. Noticeably, patients dropping out of the study had significantly higher levels of behavioural problems at baseline than patients remaining in the study and, as a consequence, their caregivers felt emotionally more burdened. Furthermore, caregivers who dropped out rated the aspects of their premorbid relationship significantly more positively than caregivers remaining in the study.

\section{Measures}

\section{Patient Characteristics}

Sociodemographic characteristics included gender, age, duration of dementia in months and the patient's domicile (home or nursing home). Severity of dementia was measured by the Global Deterioration Scale [24]. Scores range from 1 (not at all) to 7 (highest level of severity) and correspond to the 7 stages of dementia. Behavioural problems were assessed using the NPI [25], which measures 10 domains of neuropsychiatric disturbance with scores ranging from 1 ('slightly') to 12 ('extremely'): delusions, hallucinations, agitation, depression, anxiety, euphoria, apathy, disinhibition, irritability and aberrant motor behaviour; this adds up to a total score for neuropsychiatric disturbance. To minimize administration time, the screening strategy of exploring in depth only behavioural problems with positive responses was applied. The Dutch version of the NPI was proven to be reliable and valid [26]. All measures were administered at baseline and 24 months except for the NPI and Global Deterioration Scale. If the patient had deceased during the follow-up, these were not administered at 24 months.

\section{Caregiver Characteristics}

Sociodemographic characteristics included gender, age, educational level and occupation. Caregiver burden due to neuropsychiatric disturbance of the patient was measured using the NPI [25]. The caregiver was asked to rate the distress experienced in response to neuropsychiatric disturbance on a 6-point Likert scale ranging from 0 ('not at all') to 5 ('extremely') for each of the 10 domains. These ratings add up to a total distress score, with a maximum of 50. Burden of caregiving in general was measured by rating the question: 'How is taking care of the patient burdening you?' on a visual analogue scale ranging from 0 ('not at all') to 10 ('extremely'). Caregivers were also asked to rate this burden when the patient had already died. At times 1 and 2, caregivers were asked to indicate on a dichotomous scale $(1=$ yes $/ 0=$ no $)$ whether they were currently suffering from problems with their physical and mental health. At 6, 12 and 18 months of follow-up, caregivers were asked to rate their physical and mental health on a visual analogue scale ranging from 0 ('extremely poor') to 10 ('extremely well') and on a dichotomous scale whether or not ( $1=$ yes $/ 0=$ no) their physical and mental health was negatively influenced by the caregiving task.

The 90-item Revised Symptom Checklist (SCL-90-R) [27] was used to measure general psychopathology during the preceding week. The SCL-90-R comprises 8 dimensions of psychological symptoms: 'interpersonal sensitivity', 'depression', 'anxiety', 'hostility', 'agoraphobia', 'somatization', 'insufficiency of thoughts and actions' and 'sleeping disturbances', ranging from 0 ('not at all') to 4 ('extremely') which add up to a general psychopathology score. Reliabilities were satisfactory with $\alpha$ ranging from 0.73 to 0.97 .

The 36 items of the Short Form 36 health survey questionnaire (SF-36) measured health-related quality of life [28] and add up to a physical component summary (PCS) and a mental component summary (MCS). Scores on each dimension range from 0 (worst possible health state) to 100 (best possible health state). The SF-36 has been tested and has satisfactory validity [29]. PCS and MCS reliabilities at baseline were 0.82 and 0.85 , respectively.

The Utrecht Coping List measures 7 coping strategies: 'seeking distraction' (8 items), 'expressing emotions' (3 items), 'seeking social support' (6 items), 'avoiding' ( 8 items), 'fostering reassuring thoughts' (5 items), 'depressive reaction pattern' ( 7 items) and 'active coping' (7 items) [30]. Caregivers rated the 44 items on a 4 point scale ranging from 1 ('hardly ever use this strategy') to 4 ('very often use this strategy'). Its validity has been established [31], and the reliabilities in this study ranged from 0.61 to 0.88 .

The Social Support List has proven validity [32] and was used to measure the extent to which caregivers received social support (i.e. everyday emotional interactions, emotional support with respect to problems, instrumental interactions, confirmation, social companionship and informative support; 34 items) and experienced negative social interactions ( 7 items) on a scale ranging from 1 ('seldom or never') to 4 ('very often'). Reliabilities in the current study were 0.90 and 0.88 , respectively.

At baseline the quality of the relationship before the patient became demented (premorbid), of the current relationship with the patient and that at 24 months were measured on visual analogue scales ranging from 0 ('extremely poor') to 10 ('extremely well'). Four items of the University of Southern California Longitudinal Study of Three-Generation Families measures of positive affect [33] were used to rate on a 4-point response option ranging from 0 ('not at all') to 3 ('very much') 4 domains of relationship quality: connectedness (How close do you feel to the patient?), communication (How is the communication between you and the patient; how well are you able to exchange ideas and talk about the things that keep you occupied?), viewpoints (To what extent do you and the patient have the same viewpoint on life?) and getting along (How well do you and the patient get along with each other?).

\section{Statistical Analyses}

In a previous study [unpubl. data] we found important differences in patient variables associated with residence: the majority of FTD patients living at home (FTDH) had dementia of shorter duration and still showed some independence compared to FTD patients residing in a nursing home (FTDN). In FTDH patients, neuropsychiatric symptoms were more often present whereas apathy and disinhibition were more intense in FTDN patients. Therefore these variables are presented separately for FTDH and FTDN patients. Caregivers of FTDH and FTDN patients at baseline showed only marginally different variables in the same study, and therefore these results are not presented separately but the analyses of caregiver variables were adjusted for patient domicile. 
When an effect of domicile was found, the differences were inspected.

The SPSS 11.0 statistical package was used to analyse data. Independent-sample $t$ tests were performed to detect differences in NPI scores at baseline between patients residing at home, in a nursing home and who were dead at 24 months. Repeated-measure ANOVAs were performed to inspect the course of patient variables. Paired-sample t tests exclude drop-outs from the analyses and were inspected to assess differences between dementia severity, physical and mental health at times 1 (baseline) and 2 (24 months) and the impact of caregiving on their own mental and physical health at times 1 and 2. Due to the small sample size, the differences between neuropsychiatric symptoms at times 1 and 2 were only tested for the total amount of symptoms. The correlation between dementia severity and neuropsychiatric symptoms at times 1 and 2 was inspected. In multiple linear regression analyses, the quality of the relationship at baseline was estimated cross-sectionally from the quality of the premorbid relationship, type of relationship to the patient, dementia duration, caregiver and patient gender and caregiver and patient age. SAS Proc Mixed (version 8.2) was used to explore the course of the caregiver variables (caregiver burden, psychological complaints, coping strategies, social support, health-related quality of life and quality of the relationship) over the 2-year follow-up. The method of estimation was random regression modelling for repeated measurements, with the time trend as fixed covariable and the error structure defined as unstructured. The analyses were adjusted for domicile, type of relationship to the patient, dementia duration, caregiver and patient gender and caregiver and patient age. All analyses were tested at the 0.05 significance level (two-sided).

\section{Results}

\section{Patient Characteristics}

Ten out of the 29 FTD patients living at home at baseline were still living at home after the 2-year follow-up, 7 had been placed in a nursing home, 5 were deceased and 7 were lost to follow-up. Twenty-two out of the 34 FTD patients living in a nursing home were still living there, 9 were deceased and 3 were lost to follow-up.

As displayed in table 2, the majority of patients were male. At baseline, patients were on average 60.7 years old and had been demented for on average 6.7 years. The duration of dementia at baseline was significantly shorter $(\mathrm{p}<0.05)$ for patients who were still living at home at 24 months (mean 4.9; SD 1.8) than for patients who were admitted in a nursing home (mean 7.7; SD 2.9) or deceased (mean 8.7; SD 4.4) at 24 months.

At baseline, 2 patients had dementia severity score 3 on the Global Deterioration Scale rating scale, 6 severity score 4,9 severity score 5,26 had severity score 6 and 20 had severity score 7 . Dementia severity in all patients over the 2-year follow-up period significantly $(\mathrm{p}<0.001)$ increased from 5.7 (SD 1.2) to 6.5 (SD 0.7), more rapidly so
Table 2. Patient and caregiver characteristics at baseline stratified by domicile

\begin{tabular}{|c|c|c|c|}
\hline & $\begin{array}{l}\text { FTDH } \\
(n=29)\end{array}$ & $\begin{array}{l}\text { FTDN } \\
(\mathrm{n}=34)\end{array}$ & $\begin{array}{l}\text { FTD total } \\
(\mathrm{n}=63)\end{array}$ \\
\hline \multicolumn{4}{|l|}{ Patients } \\
\hline Males & $11(38)$ & $18(53)$ & $39(62)$ \\
\hline Mean age, years & $60.0 \pm 8.6$ & $61.2 \pm 10.5$ & $60.7 \pm 9.6$ \\
\hline \multicolumn{4}{|c|}{ Mean duration of dementia, } \\
\hline \multicolumn{4}{|l|}{ Caregivers } \\
\hline Males & $11(38)$ & $18(53)$ & $29(38)$ \\
\hline Mean age, years & $57.1 \pm 10.7$ & $57.1 \pm 12.5$ & $57.1 \pm 11.6$ \\
\hline \multicolumn{4}{|l|}{ Educational level } \\
\hline Low & $8(29)$ & $10(29)$ & $18(18)$ \\
\hline Medium & $11(40)$ & $14(41)$ & $25(40)$ \\
\hline High & $9(31)$ & $10(30)$ & $19(30)$ \\
\hline \multicolumn{4}{|c|}{ Type of relationship to patient } \\
\hline Spouse & $27(93)$ & $24(71)$ & $51(81)$ \\
\hline Child & $2(7)$ & $10(29)$ & $9(14)$ \\
\hline
\end{tabular}

Results are presented as means $\pm \mathrm{SD}$, or numbers with percentages in parentheses.

in FTDH patients, i.e. from 4.9 (SD 1.2) to 5.9 (SD 0.8; $\mathrm{p}<0.001)$. The progress of dementia in FTDN patients approached the maximal level on the severity scale of 6.6 (SD 0.5) to 6.9 (SD 0.2; p < 0.01). At baseline the dementia severity was significantly lower $(\mathrm{p}<0.01)$ for patients who lived at home during the follow-up (mean 4.6; SD 1.5) than for patients who lived in a nursing home (mean 6.0 ; SD 0.9) or died (mean 6.2; SD 1.0) during the followup.

The total score of neuropsychiatric symptoms showed a non-significant decrease from 25.1 (SD 13.5) to 20.4 (SD 7.7). Dementia severity and neuropsychiatric disturbance (the latter measured as the number of symptoms) at baseline showed no association $(\mathrm{r}=-0.07)$. At 24 months the association between dementia severity and neuropsychiatric disturbance was $r=-0.65(p<0.001)$. Figure $1 \mathrm{dem}-$ onstrates a declining tendency in the frequency of neuropsychiatric symptoms as measured by the NPI at times 1 and 2.

T-tests for independent observations demonstrated that at baseline the NPI total score was significantly lower $(\mathrm{p}<0.05)$ for patients who were still living at home at 24 months (mean 12.7; SD 4.6) than for patients who were in a nursing home (mean 24.5; SD 13.0) or deceased (mean 27.5; SD 14.5) at 24 months. 


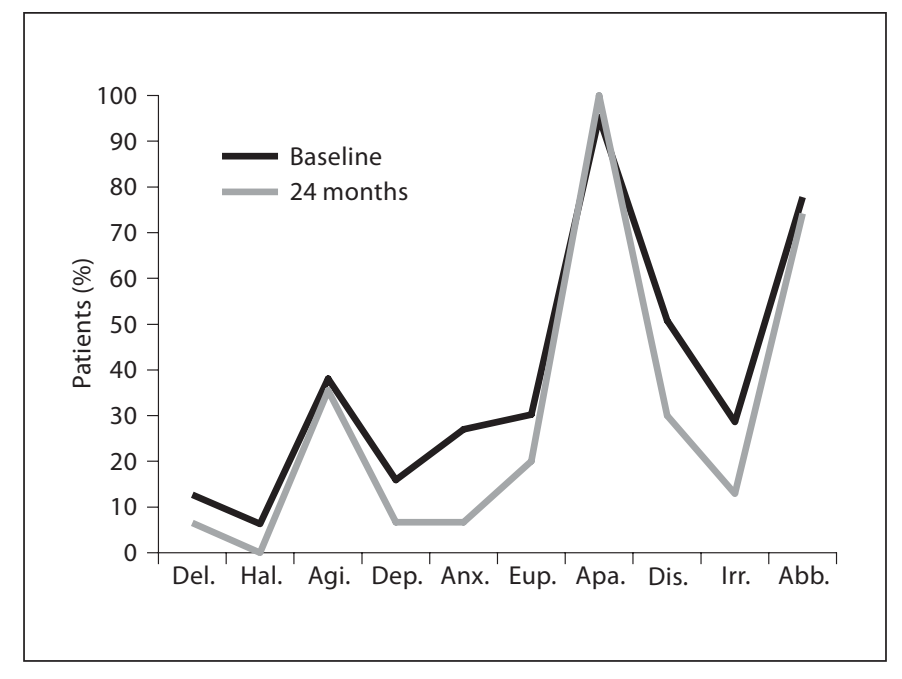

Fig. 1. Presence of neuropsychiatric symptoms from time 1 to time 2 expressed as percentage of patients with these neuropsychiatric symptoms compared to the total group. Subscales of the NPI. del. = delusions; hal. = hallucinations; agi. = agitation; dep. = depression; anx. = anxiety; eup. = euphoria; apa. = apathy; dis. $=$ disinhibition; irr. = irritability; abb. = abberrant motor behaviour.

\section{Caregiver Characteristics}

As displayed in table 2, 38\% of caregivers were female. At baseline caregivers were on average 57.1 years old (range 32-77 years) and 18\% had completed low, $40 \%$ medium and $30 \%$ higher-level education; of the remaining $12 \%$ the educational level was unknown. A total of $81 \%$ were spouses of the patients and $14 \%$ were children of the patients.

The emotional burden caused by neuropsychiatric symptoms (NPI) decreased significantly $(\mathrm{p}<0.01)$ from baseline $($ mean $=9.4 ;$ SD 6.8$)$ to 24 months $($ mean $=6.4$; SD 4.9).

The overall caregiver burden for all caregivers decreased significantly $(\mathrm{p}<0.01)$ during the 2 years (baseline mean $=5.6, \mathrm{SD} 2.6$, and 24 months mean $=4.2, \mathrm{SD}$ $2.8)$. There was a significant effect for domicile $(\mathrm{p}<0.05)$. Figure 2 demonstrates the average levels of general caregiver burden as experienced by FTDH caregivers, FTDN caregivers and caregivers of deceased FTD patients at baseline and 24 months. Although only the difference at 24 months between FTDH caregivers and caregivers of deceased patients was significant $(\mathrm{p}<0.01)$, figure 2 clearly shows differing tendencies for caregiver burden. The FTDH caregivers tend to experience more burden over time whereas the FTDN caregivers and caregivers of deceased patients show declining burden.

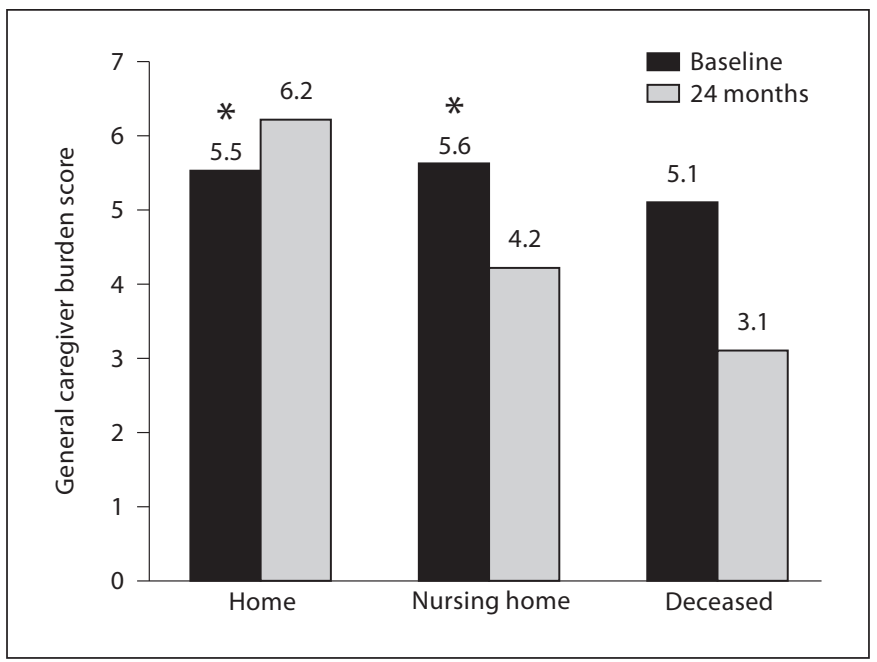

Fig. 2. Overall caregiver burden differentiated by domicile. Asterisks indicate significance.

Caregivers of patients living at home during the 2-year follow-up had an average burden of 5.8. Caregivers of patients who were admitted in a nursing home at some point during the follow-up had an average burden score of 6.4, whereas caregivers of patients living in a nursing home during the complete follow-up period had an average burden score of 5.4. Once patients were deceased, their caregivers reported an average burden of 3.1.

Caregivers experienced significant $(\mathrm{p}<0.05)$ improvement in their physical health (baseline mean $=6.9, \mathrm{SD} 1.6$; 24 months mean $=7.3$, SD 1.2) and mental health (baseline mean $=6.7$, SD 1.6; 24 months mean $=7.4, \mathrm{SD} 1.2$ ). At baseline $77 \%$ of caregivers reported a negative influence of caregiving on their mental health, as opposed to $56 \%$ at 24 months $(\mathrm{p}<0.05)$.

There was no significant change in psychological complaints (SCL-90-R) during the follow-up. The sum score for the SCL-90-R was on average 125.5, which is above average compared to the general population but below average when compared to patients visiting a general practitioner [34].

There was no significant change in the physical and mental components of health-related quality of life (SF36).

With respect to coping strategies, all were used to a similar degree from baseline to 24 months except for depressive reaction, which increased significantly from baseline to 24 months $(\mathrm{p}<0.05)$. Emotional expression was used significantly more $(\mathrm{p}<0.001)$ by FTDN caregivers than FTDH caregivers. 


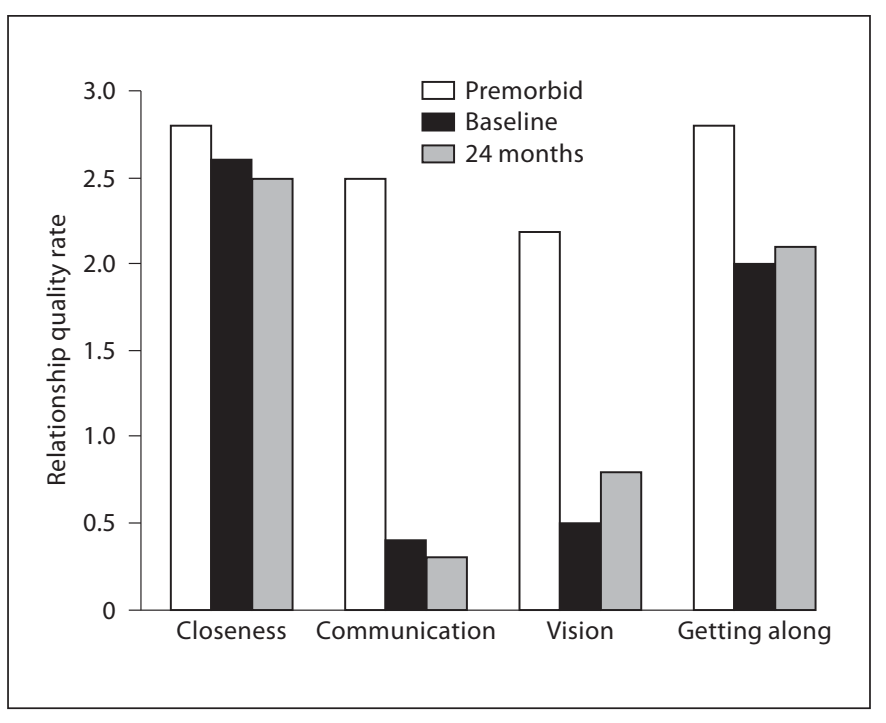

Fig. 3. Course of the evaluation of the components of relationship quality rated retrospectively at times 1 and 2 and retrospectively for when the patient was unaffected.

Interactions with the environment did not change over time: social support and negative interactions were experienced similarly by caregivers, with more instrumental support than negative interactions (mean $=73.4$, SD 14.1, and mean $=9.6$, SD 3.2, at baseline). FTDN caregivers experienced more negative interactions than FTDH caregivers albeit marginally significant $(\mathrm{p}<0.07)$.

Caregivers rated the premorbid relationship components of closeness $(\mathrm{p}<0.06)$, communication $(\mathrm{p}<0.001)$, viewpoint $(\mathrm{p}<0.001)$ and getting along $(\mathrm{p}<0.001)$ as better than baseline (fig. 3). Between baseline and 24 months there were no significant changes in the aspects of the relationship. Caregivers rated the quality of the premorbid relationship as significantly $(\mathrm{p}<0.001)$ better than at baseline $($ mean $=8.3$, SD 1.6, and mean $=5.6$, SD 3.1, respectively). From baseline to 24 months, the quality of the relationship was unchanged.

\section{Discussion}

In the current study we addressed the course of caregiver burden and relationship quality in family caregivers of FTD patients over a period of 2 years. In terms of caregiver burden we specifically focused on the domains of psychological and social well-being.

Increasing neuropsychiatric disturbance and dementia severity are known to be associated with increased caregiver burden [4-8]. During the 2-year follow-up FTD severity progressed significantly. FTDH patients who still had knowledge of the most important facts of their lives and who did not require help with eating and toileting had progressed into unawareness of themselves and others and needing help with daily living activities. FTDN patients approached the severest level of dementia, meaning that from being completely dependent but still differentiating familiar from unfamiliar faces and being continent they progressed to incontinence, aphasia and loss of psychomotor skills. Despite the progress in dementia severity, the total load of neuropsychiatric symptoms patients presented remained stable. This contrasts with the earlier described findings that neuropsychiatric disturbance increased as dementia worsened [11,12]. A possible explanation may be that the patients in our sample were no longer capable of presenting neuropsychiatric symptoms once they reached the highest measurable levels of dementia severity.

Furthermore, despite the increase in dementia severity both general caregiver burden and emotional burden caused by the patient's neuropsychiatric symptoms decreased. There was, however, a moderating effect for patient residence; FTDH caregivers showed an increasing tendency in the overall caregiver burden they experienced which may be explained by the observation that FTDH patients showed the greatest deterioration in functional abilities. Other studies have also found stable levels of caregiver burden despite increased dementia severity and neuropsychiatric symptoms $[14,16]$. It may be that levels of burden decreased because levels of symptoms remained stable and caregivers learned to adapt to these symptoms during the observation period. Burden is known to peak around the process of nursing home admission [35, 36], but FTD caregivers rated their burden as a mere 6.4 on a scale of $0-10$. Alternatively, this suggests that caregivers may have been reluctant to admit to caregiver burden because it would imply failure in the caregiving role. Caregivers of deceased patients reported the lowest burden although the burden did not disappear. Once the patient has died there is no more need for active coping. It is our clinical impression that these caregivers experience a burdening emptiness in which they are confronted with what they have been through during their caregiving years.

The literature on caregiver burden in Alzheimer's disease reports stable levels of psychological well-being and quality of life over time [13-16]. However, given the more 'frontal' clinical features of FTD and our clinical impressions, we did not assume that this would be similar in 
FTD. We found that psychological well-being in terms of psychological complaints, health-related quality of life and received social support remained stable during the 2-year follow-up, which is congruent with the literature on Alzheimer's disease. In addition, both FTDH and FTDN caregivers reported improvements in their psychological and physical well-being and reported a decrease in the negative influence of their caregiving activities on psychological and physical well-being. Here we must mention that we observed a discrepancy between how caregivers present themselves face to face as opposed to presentation through our questionnaires. Our impression from meetings organized especially for FTD caregivers and from the clinic is that FTD caregivers feel highly burdened and often state that they are reaching their limits. However, as becomes clear from this study, we did not find the maximum burden or deterioration in psychological well-being in our analyses. Therefore, instead of feeling encouraged by these results we must acknowledge the possibility that our results were masked by response shift, a means of psychological adjustment. Response shift implies that an individual adapts his internal standards, values and concept of quality of life to accommodate hardships in life such as disease [37]. Thus, in the current study the caregivers may have adapted to the increased burden and decreased psychological well-being by changing the internal standards used to rate these outcome variables, thereby providing stable or even slightly improved outcomes. The actual burden and adaptational process behind these scores then remain invisible to the researcher. The fact that studies into caregiver burden in other dementias report similar burden trends may also be suggestive of response shift. We therefore strongly recommended that future longitudinal research on caregiver burden incorporate research methods that take into account the response shift phenomenon. It is our expectation that the burden that caregivers do experience will then become apparent and also how caregivers adapt to this burden, thereby creating insights into how these caregivers may best be supported.

In the current study we furthermore inspected the evolution of coping to enhance our understanding of caregiver burden. All caregivers displayed an increased depressive reaction pattern during the study period. Another study also reports that depressive reactions were specifically noted in spouses of FTD patients, when compared with those of other dementia cases [38]. The depressive reaction includes depressive feelings about the future, and feeling oneself both preoccupied and in- capable of dealing with the situation. In addition, we found an increased use of emotional expression, particularly in FTDN caregivers. FTDN caregivers furthermore experienced an increase in negative social interactions. Emotional expression concerns the venting of negative emotions such as frustration and anger, which may have damaged potentially supportive social relationships. It would thus seem that FTD caregivers would benefit from support in employing adequate coping strategies. We recommend that psychosocial workers who encounter FTD caregivers pay attention to how they cope with their negative emotions in a social context.

Finally, we explored the evolution of the quality of the caregiver-care recipient relationship. FTD caregivers reported high quality of the premorbid relationship, which may have had a buffering effect on caregiver burden [19]. Similar observations were reported in caregivers of patients with Alzheimer's disease [20]. Strikingly, the overall quality of the relationship, closeness and getting along were unaffected during the follow-up. Communication and sharing viewpoints on life with the patient were however dramatically reduced. For these latter aspects, active communication and input of the patient are required, whereas for the aspects of closeness and getting along caregivers may rely mostly on their own feelings of closeness and their unidirectional efforts to get along with the patient. The preservation of these aspects of the relationship, independently of the patient, might have nourished the caregiver's ability to provide such intense care. More research is needed to validate these exploratory findings on the possibly favourable impact on the caregiver of preserving some aspects of the partner relationship.

A few important limitations to our study need to be mentioned. The sample size of our study was small due to the low prevalence of FTD in our population, which is unfavourable for detecting significant differences in statistical analyses. Furthermore, a total of 24 out of 63 caregiving dyads dropped out of the study. Ten dropped out for unknown reasons, and these dyads had higher scores on neuropsychiatric disturbance and subsequent burden, which is suggestive of selective drop-out and therefore a threat to the generalizability of our results. 


\section{Conclusions}

In inspecting FTD caregivers over a 2 -year period, we may conclude that contrary to our expectations caregiver burden, psychological well-being, health-related quality of life and relationship quality remained remarkably stable during the observation period. This might be indicative of caregiver adaptation; however, future research should adopt methods that reveal response shift in order to validate these findings. Furthermore, FTD caregivers require support in dealing with the increasingly hopeless situation of the patient and in constructively coping with negative emotions.

\section{Acknowledgements}

We thank all participating FTD patients and their caregivers for their contribution to the study. Furthermore, we thank Jacqueline Mourik for her contribution to the study design and data collection. The Dutch Research Council has supported this study (NWO: 940-38-005).

\section{References}

1 Rosso SM, Donker Kaat L, Baks T, Joosse M, de Koning I, Pijnenburg Y, de Jong D, Dooijes D, Kamphorst W, Ravid R, Niermeijer MF, Verheij F, Kremer HP, Scheltens P, van Duijn CM, Heutink P, van Swieten JC: Frontotemporal dementia in the Netherlands: patient characteristics and prevalence estimates from a population-based study. Brain 2003; 126:2016-2022.

-2 Snowden JS, Neary D, Mann A: Frontotemporal dementia. Br J Psychiatry 2002;180: 140-143.

-3 Sorensen S, Duberstein P, Gill D, Pinquart M: Dementia care: mental health effects, intervention strategies, and clinical implications. Lancet Neurol 2006;5:961-973.

4 Andrieu S, Balardy L, Gillette-Guyonnet S, Bocquet H, Cantet C, Albarede JL, Vellas B, Grand A: Informal caregiver's burden of Alzheimer's patients: assessment and factors associated. Rev Méd Interne 2003;24:351S359S.

5 Zanetti O, Frisoni GB, Bianchetti A, Tamanza G, Cigoli V, Trabucchi M: Depressive symptoms of Alzheimer caregivers are mainly due to personal rather than patient factors. Int J Geriatr Psychiatry 1998;13:358-367.

6 Rymer S, Salloway S, Norton L, Malloy P, Correia S, Monast D: Impaired awareness, behavior disturbance, and caregiver burden in Alzheimer disease. Alzheimer Dis Assoc Disord 2002;16:248-253.

$\checkmark 7$ Aguglia E, Onor ML, Trevisiol M, Negro C, Saina M, Maso E: Stress in the caregivers of Alzheimer's patients: an experimental investigation in Italy. Am J Alzheimers Dis Other Demen 2004;19:248-252.

$\checkmark 8$ Hooker K, Bowman SR, Coehlo DP, Lim SR, Kaye J, Guariglia R, Li FZ: Behavioral change in persons with dementia: relationships with mental and physical health of caregivers. J Gerontol Ser B Psychol Sci Soc Sci 2002;57: P453-P460.
$>$

Rymer S, Salloway S, Norton L, Malloy P, Correia S, Monast D: Impaired awareness, behavior disturbance, and caregiver burden in Alzheimer disease. Alzheimer Dis Assoc Disord 2002;16:248-253.

10 Davis JD, Tremont G: Impact of frontal systems behavioral functioning in dementia on caregiver burden. J Neuropsychiatry Clin Neurosci 2007;19:43-49.

-11 Steffens DC, Maytan M, Helms MJ, Plassman BL: Prevalence and clinical correlates of neuropsychiatric symptoms in dementia. Am J Alzheimer Dis Other Demen 2005;20: 367-373.

12 Diehl-Schmid J, Pohl C, Perneczky R, Forstl $\mathrm{H}$, Kurz A: Behavioral disturbances in the course of frontotemporal dementia. Dement Geriatr Cogn Disord 2006;22:352-357.

13 Heru AM, Ryan CE, Iqbal A: Family functioning in the caregivers of patients with dementia. Int J Geriatr Psychiatry 2004;19: 533-537.

14 Berger G, Bernhardt T, Weimer E, Peters J, Kratsch T, Frolich L: Longitudinal study on the relationship between symptomatology of dementia and levels of subjective burden and depression among family caregivers in memory clinic patients. J Geriatr Psychiatry Neurol 2005; 18:119-128.

15 Tibaldi V, Aimonino N, Costamagna C, Obialero R, Ruatta C, Stasi MF, Molaschi M: Clinical outcomes in elderly demented patients and caregiver's stress: a 2-year followup study. Arch Gerontol Geriatr 2007; 44(suppl 1):S401-S406.

16 Danhauer SC, McCann JJ, Gilley DW, Beckett LA, Bienias JL, Evans DA: Do behavioral disturbances in persons with Alzheimer's disease predict caregiver depression over time? Psychol Aging 2004;19:198-202.
17 Andren S, Elmstahl S: Family caregivers' subjective experiences of satisfaction in dementia care: aspects of burden, subjective health and sense of coherence. Scand J Caring Sci 2005;19:157-168.

18 Lundh U: Sources of satisfaction among Swedish carers. Br J Nurs 1999;8:647-652.

19 Steadman PL, Tremont G, Davis JD: Premorbid relationship satisfaction and caregiver burden in dementia caregivers. J Geriatr Psychiatry Neurol 2007;20:115-119.

20 De Vugt ME, Stevens F, Aalten P, Lousberg R, Jaspers N, Winkens I, Jolles J, Verhey FR: Behavioural disturbances in dementia patients and quality of the marital relationship. Int J Geriatr Psychiatry 2003;18:149-154.

$>21$ Spruytte N, Van Audenhove C, Lammertyn F: Predictors of institutionalization of cognitively impaired elderly cared for by their relatives. Int J Geriatr Psychiatry 2001;16:11191128.

$\checkmark 22$ Clinical and neuropathological criteria for frontotemporal dementia. The Lund and Manchester Groups. J Neurol Neurosurg Psychiatry 1994;57:416-418.

23 Rosso SM, Roks G, Stevens M, de Koning I, Tanghe HLJ, Kamphorst W, Ravid R, Niermeijer MF, van Swieten JC: Complex compulsive behaviour in the temporal variant of frontotemporal dementia. J Neurol 2001; 248:965-970.

24 Reisberg B, Ferris SH, de Leon MJ, Crook T: The Global Deterioration Scale for assessment of primary degenerative dementia. Am J Psychiatry 1982;139:1136-1139.

25 Cummings JL, Mega M, Gray K, RosenbergThompson S, Carusi DA, Gronbein J: The Neuropsychiatric Inventory: comprehensive assessment of psychopathology in dementia. Neurology 1994;44:2308-2314. 
26 De Jonghe JF, Kat MG, Kalisvaart CJ, Boelaarts L: Neuropsychiatric inventory questionnaire (NPI-Q): A validity study of the Dutch form. Tijdschr Gerontol Geriatr 2003; 32:74-77.

-27 Derogatis LR, Cleary PA: Factor invariance across gender for the primary symptom dimensions of the SCL-90-R. Br J Soc Clin Psychol 1977;16:347-356.

28 Ware JE, Snow KK: SF-36 Health Survey: Manual and Interpretation Guide. Boston, Health Institute, New England Medical Center, 1993.

-29 McHorney CA, Ware JE Jr, Raczek AE: The MOS 36-Item Short-Form Health Survey (SF-36). II. Psychometric and clinical tests of validity in measuring physical and mental health constructs. Med Care 1993;31:247263.
30 Schreurs PJG: De Utrechtse Coping Lijst (UCL): omgaan met problemen en gebeurtenissen. Lisse, Swets \& Zeitlinger, 1993.

31 Sanderman R, Ormel J: De Utrechtse Coping Lijst (UCL): validiteit en betrouwbaarheid. Gedrag en Gezondheid 1992;20:32-37.

32 Van Sonderen FLP: Het meten van sociale steun met de Sociale Steun Lijst-Interacties (SSL-I) en Sociale Steun Lijst-Discrepanties (SSL-D): een handleiding. Groningen, Noordelijk Centrum voor Gezondheidsvraagstukken, 1993.

- 33 Lawrence RH, Tennstedt SL, Assmann SF: Quality of the caregiver-care recipient relationship: does it offset negative consequences of caregiving for family caregivers? Psychol Aging 1998;13:150-158.

34 Arrindell WA, Ettema JHM: SCL-90 handleiding bij een multidimensionele psychopathologie indicator, ed 3. Enshede, Swets test publishers, 2003.
35 Gaugler JE, Kane RL, Kane RA, Newcomer $\mathrm{R}$ : The longitudinal effects of early behavior problems in the dementia caregiver career. Psychol Aging 2005;20:100-116.

36 Yaffe K, Fox P, Newcomer R, Sands L, Lindquist K, Dane K, Covinsky KE: Patient and caregiver characteristics and nursing home placement in patients with dementia. J Am Med Assoc 2002;287:2090-2097.

-37 Sprangers MAG, Schwartz CE: Integrating response shift into health-related quality of life research: a theoretical model. Soc Sci Med 1999;48:1507-1515.

38 Kaiser S, Panegyres PK: The psychosocial impact of young onset dementia on spouses. Am J Alzheimer Dis Other Demen 2007;21: 398-402. 